\title{
NECROLÓGIO
}

\section{João M. F. Camargo - um naturalista dedicado às abelhas (20.06.1941 - 07.09.2009)}

Pontinhos, milhares deles, e dias depois, após horas ininterruptas de trabalho com a pena e o nanquim, lá estava: uma perfeita representação das obras arquitetônicas das abelhas, um magnífico ninho, composto por milhares de pontos, ilustrando milhões de anos de evolução. Era assim que o Professor Camargo, sempre impecável, nas suas camisas de linho, passava a maior parte do dia, ou desenhando, ou observando na lupa, preciosos detalhes nas formas das abelhas, em sua mesa de bálsamo (talhada "na enxó", por ele mesmo - mais uma obra de arte!), na sua sala, ao lado da coleção de abelhas, na Faculdade de Filosofia, Ciências e Letras de Ribeirão Preto, Universidade de São Paulo; isso, quando não estava no mato, estudando e coletando abelhas-era assim que ele se sentia mais a vontade.

Em tudo o que fazia, havia muita dedicação, quer nos desenhos, quer nos trabalhos científicos, ou nos cuidados com a coleção de abelhas que ele começou a montar nos idos de 1963, com apoio do Dr. W. E. Kerr, que o convidou para uma expedição aos arredores de Manaus. Nesta ocasião, teve seu primeiro contato com floresta e com as belíssimas construções produzidas pelas abelhas, e que foram tão perfeitamente ilustradas por ele (Kerr et al. 1967). Os exemplares coletados naquela ocasião foram identificados pelo Pe. J. S. Moure e "constituíram o embrião da atual coleção", como relatado por ele mesmo em seu Memorial. Em $1966 \mathrm{fez}$ uma viagem solo, de 10 dias, à região de Porto Velho, onde estudou, em detalhe, os ninhos de 10 espécies de Meliponini, e que resultou em sua primeira publicação individual (Camargo 1970). A partir daí, foram inúmeras viagens e expedições científicas, que contribuíram para a montagem do acervo de uma das mais importantes coleções de Meliponini Neotropicais do mundo a única que inclui também peças das obras construídas por essas abelhas - com mais de 800 ninhos meticulosamente estudados. Mantinha um bom relacionamento com pesquisadores do Brasil e do exterior o que propiciou a incorporação ao acervo de duplicatas da coleção Moure e da coleção Schwarz, inclusive espécimes-tipo, e conferiu maioridade e reconhecimento da coleção em nível internacional. Daí em diante, o intercâmbio constante, além de viagens e levantamentos, permitiu enriquecer consideravelmente a coleção, atualmente sediada no Departamento de Biologia da FFCLRP. Este talvez seja o legado mais precioso para as futuras gerações de estudiosos das abelhas.

Iniciou-se na carreira científica em 1961, quando foi contratado como desenhista pela Faculdade de Filosofia, Ciências e Letras de Rio Claro (atual UNESP) e teve contato com um grupo forte de pesquisa em genética, biologia e taxonomia de abelhas, liderado pelo Dr. Kerr, e com

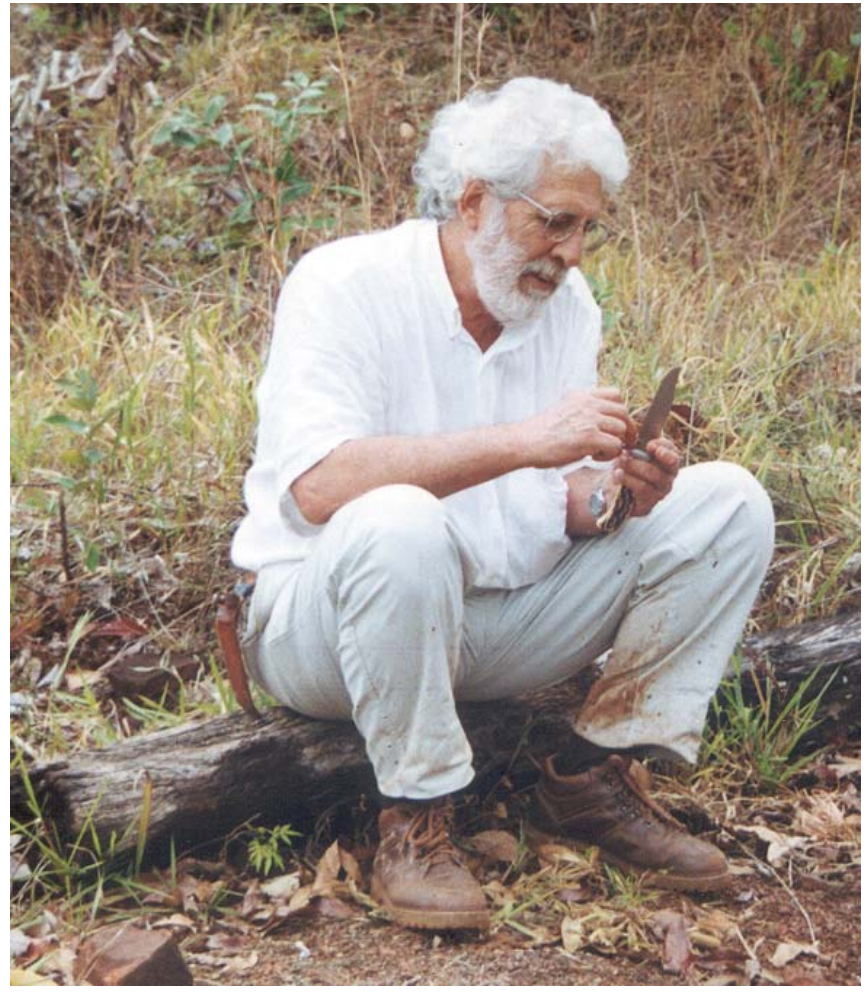

J. M. F. Camargo, em viagem de coleta a Pedregulho-SP, 01/09/2002.

pesquisadores convidados, como S. F. Sakagami, com quem publicou seu primeiro trabalho (Sakagami \& Camargo 1964). Nesse período, além de ilustrar dezenas de artigos para vários pesquisadores, iniciou suas próprias pesquisas com abelhas, como o estudo sobre a morfologia externa de Melipona marginata Lepeletier (Camargo et al. 1967), que incluía pranchas desenhadas por ele, impressas em tamanho grande, para serem afixadas em paredes de laboratórios e salas de aula, além de uma operária colorida a guache - uma obra de referência para estudiosos da morfologia de abelhas. A partir de 1965 foi contratado pela Faculdade de Medicina de Ribeirão Preto. Nesse período, dedicou-se em grande parte, ao estudo das abelhas africanizadas, morfologia, técnicas de inseminação artificial e apicultura, o que resultou em vários artigos e na editoração do livro Manual de Apicultura (Camargo 1972), com três capítulos de sua autoria, além de trabalhos com outras abelhas. Cursou o mestrado em Entomologia na Universidade Federal do Paraná, estudando a diferenciação geográfica das espécies amarelas de Partamona Schwarz, sob orientação do Pe. Moure, e a dissertação resultante foi publicada integralmente (Camargo 1980).

Foi contratado como Professor Visitante na Universidade Federal do Maranhão em 1981, e, mais tarde, de volta a Ribeirão Preto, assumiu a disciplina de Entomologia Geral I no curso de 
Pós-Graduação em Entomologia da FFCLRP, onde foi contratado como técnico de nível superior. O doutorado veio em 1991, com o estudo da sistemática e comportamento dos Meliponini necrófagos obrigatórios, e em 1996, foi concursado como Professor Doutor. Não media esforços na preparação das aulas, e também na orientação de seus alunos de mestrado e doutorado, o que resultou em oito dissertações e oito teses, além de várias monografias de graduação e supervisão de dois pós-doutorados.

Em 45 anos de dedicação a ciência, foram muitas as contribuições para a sistemática e comportamento das abelhassem-ferrão: 89 publicações, coincidentemente, também foram 89 os táxons publicados por ele (três gêneros e 86 espécies), todos de abelhas-sem-ferrão, com uma única exceção: Xylocopa (Neoxylocopa) suspecta Moure \& Camargo. Revisou a sistemática e comportamento de nidificação de vários gêneros, resultando em artigos ricamente ilustrados $(e$. g. Camargo \& Moure 1994; Camargo \& Pedro 2003). A descoberta de uma nova espécie, Trichotrigona extranea Camargo \& Moure, com peculiaridades morfológicas e comportamentais - não constrói potes, nem armazena qualquer tipo de alimento -, levou a publicação de um novo gênero (Camargo \& Moure 1983; Camargo \& Pedro 2007a). Deu a conhecer, também, outros comportamentos inusitados para os Meliponini, como a estocagem de pólen associado com leveduras, que promovem a dessecação e longevidade na ensilagem, só conhecida em espécies de Ptilotrigona Moure (Camargo et al. 1992; Camargo \& Pedro 2004), as abelhas necrófagas obrigatórias, que não coletam pólen, nem néctar floral (Camargo \& Roubik 1991), e a associação mutualística de Schwarzula coccidophila Camargo \& Pedro com cochonilhas (Camargo \& Pedro 2002).

Dono de uma acuidade singular na percepção dos pequenos detalhes, mas sem perder a visão do conjunto, Camargo foi capaz de elucidar um pouco da complexa história evolutiva dos Meliponini Neotropicais. Propôs hipóteses de filogenia para vários gêneros, traçou mapas de endemismo e definiu padrões na distribuição do grupo, propondo eventos de quebra e vicariância para explicar a atual diversidade taxonômica encontrada na região Neotropical; conjugando espaço, tempo e forma, concluiu que a Amazônia não é uma unidade histórica, mas sim composta de três grandes compartimentos biogeográficos com relações temporais e filogenéticas distintas (Camargo 2008).

Tinha, por hábito, manter sempre atualizado o seu fichário sobre os Meliponini, nos moldes daquele iniciado pelo Pe. Moure, em Curitiba, acrescentado novas referências sobre as espécies e os assuntos de que tratavam; essas informações, além de atualizações sobre a taxonomia e comentários sobre as espécies, foram compiladas em um capítulo do Catálogo Moure (Camargo \& Pedro 2007b), também disponibilizadas online.

Há que se destacar, também, os estudos sobre a bionomia de abelhas Euglossini (e.g. Zucchi et al. 1969), etnobiologia dos índios Kayapó (e.g. Camargo \& Posey 1990), comportamento de visita às flores e mecanismos de polinização (e.g. Camargo et al. 1984), além de trabalhos sobre estrutura de comunidades de abelhas visitantes de flores em diversos ambientes.

Seus magníficos desenhos de abelhas, ninhos e flores percorrem o mundo e têm sido reproduzidos em diversas publicações (e.g. Michener 1974; Gottsberger \& SilberbauerGottsberger 2006).

Perdemos um entomólogo brilhante, que soube como ninguém, retratar as mais belas obras da natureza. Seu legado artístico e científico não será esquecido. João M. F. Camargo faleceu em 07 de setembro de 2009, aos 68 anos em conseqüência de um câncer agressivo.

"Infinitas formas de grande beleza"*: era assim que ele via a natureza (*título do livro de S. B. Carroll (2006), que ele recomendava aos alunos como leitura adicional, e também o nome escolhido pela turma de formandos do curso de Ciências Biológicas da FFCLRP de 2009, que o escolheu como Professor Homenageado, pouco antes de adoecer).

Agradecimentos. Ao Prof. Dr. Gabriel A.R. Melo (Editor Associado da Revista Brasileira de Entomologia) pelo convite para escrever o necrológio do Dr. João M.F. Camargo.

\section{REFERÊNCIAS}

Camargo, J. M. F. 1970. Ninhos e biologia de algumas espécies de Meliponídeos (Hymenoptera: Apidae) da região de Pôrto Velho, Território de Rondônia, Brasil. Revista de Biologia Tropical 16: 207-239.

Camargo, J. M. F. (Org.). 1972. Manual de Apicultura. São Paulo, Editora Agronômica Ceres, $252 \mathrm{p}$.

Camargo, J. M. F. 1980. O grupo Partamona (Partamona) testacea (Klug): suas espécies, distribuição e diferenciação geográfica (Meliponinae, Apidae, Hymenoptera). Acta Amazonica 10 (4, supl.): $1-175$.

Camargo, J. M. F. 2008. Biogeografia histórica dos Meliponini (Hymenoptera, Apidae, Apinae) da região Neotropical, p. 13-26. In: P. Vit. (ed.), Abejas sin Aguijón y Valorización Sensorial de su Miel. Mérida, APIBA-DIGECEX, Universidad de Los Andes. $148 \mathrm{p}$.

Camargo, J. M. F. \& J. S. Moure.1983. Trichotrigona, um novo gênero de Meliponinae (Hymenoptera, Apidae) do rio Negro, Amazonas, Brasil. Acta Amazônica 13: 421-429.

Camargo, J. M. F. \& J. S. Moure. 1994. Meliponinae Neotropicais: Os Gêneros Paratrigona Schwarz, 1938 e Aparatrigona Moure, 1951 (Hymenoptera, Apidae). Arquivos de Zoologia, S. Paulo, 32: 33109.

Camargo, J. M. F. \& S. R. M. Pedro. 2002. Mutualistic Association Between a Tiny Amazonian Stingless Bee and a Wax-producing scale insect. Biotropica 34: 446-451.

Camargo, J. M. F. \& S. R. M. Pedro. 2003. Meliponini neotropicais: O gênero Partamona Schwarz, 1939 (Hymenoptera, Apidae, Apinae) - bionomia e biogeografia. Revista Brasileira de Entomologia 47: 311-372.

Camargo, J. M. F. \& S. R. M. Pedro. 2004. Meliponini neotropicais: o gênero Ptilotrigona Moure (Hymenoptera, Apidae, Apinae). Revista Brasileira de Entomologia 48: 353-377.

Camargo, J. M. F. \& S. R. M. Pedro. 2007 a. Notas sobre a bionomia de Trichotrigona extranea Camargo \& Moure (Hymenoptera, Apidae, Meliponini). Revista Brasileira de Entomologia 51: 72-81.

Camargo, J. M. F. \& S. R. M. Pedro 2007 b. Meliponini Lepeletier, 1836 , p. 272-578. In: J. S. Moure, D. Urban \& G. A. R. Melo, (Orgs.). Catalogue of Bees (Hymenoptera, Apoidea) in the 
Neotropical Region. Curitiba, Sociedade Brasileira de Entomologia, xiv+ $1058 \mathrm{p}$

Camargo, J. M. F. \& D. A. Posey. 1990. O conhecimento dos Kayapó sobre as abelhas sociais sem ferrão (Meliponidae, Apidae, Hymenoptera): notas adicionais. Boletim do Museu Paraense Emílio Goeldi 6: 17-42.

Camargo, J. M. F. \& D. W. Roubik. 1991. Systematics and bionomics of the apoid obligate necrophages: the Trigona hypogea group (Hymenoptera: Apidae; Meliponinae). Biological Journal of the Linnean Society 44: 13-39.

Camargo, J. M. F.; G. Gottsberger \& I. Silberbauer-Gosttsberger. 1984. On the phenology and flower visiting behavior of Oxaea flavescens (Klug) (Oxaeinae, Andrenidae, Hymenoptera) in São Paulo, Brazil. Beiträge zur Biologie der Pflanzen 59: 159-179.

Camargo, J. M. F.; W. E. Kerr \& C. R. Lopes. 1967. Morfologia externa de Melipona (Melipona) marginata Lepeletier (Hymenoptera, Apoidea). Papéis Avulsos de Zoologia 20: 229-258.

Camargo, J. M. F.; M. V. B. Garcia; R. Q. Eugênio, Jr. \& A. Castrillon. 1992. Notas prévias sobre a bionomia de Ptilotrigona lurida (Hymenoptera, Apidae, Meliponinae): associação de leveduras em pólen estocado. Boletim do Museu Paraense Emílio Goeldi 8: 391-395.

Carroll, S. B. 2006. Infinitas Formas de Grande Beleza: como a evolução forjou a grande quantidade de criaturas que habitam o nosso planeta. Rio de Janeiro, Jorge Zahar Ed., 303 p.
Gottsberger, G. \& I. Silberbauer-Gottsberger. 2006. Life in the Cerrado: A South American Tropical Seasonal Vegetation. Vol. II. Pollination and Seed Dispersal. Ulm: Reta Verlag, 384 p.

Kerr, W. E.; S. F. Sakagami; R. Zucchi; V. Portugal Araujo \& J. M. F. Camargo. 1967. Observações sobre a arquitetura dos ninhos e comportamento de algumas espécies de abelhas sem ferrão das vizinhanças de Manaus, Amazonas (Hymenoptera, Apoidea). Atas do Simpósio sobre a Biota Amazônica 5: 235-309.

Michener, C. D. 1974. The Social Behavior of the Bees. The Belknap Press of Harvard Univ. Press, Cambridge, Massachusetts. 404 p.

Sakagami, S. F. \& J. M. F. Camargo. 1964. Cerumem collection accompained by thieving and attacking in a stingless bee Nannotrigona (Scaptotrigona) postica (Latreille), with a consideration on territoriality in social insects. Revista de Biologia Tropical 12: 197-207.

Zucchi, R.; S. F. Sakagami \& J. M. F. Camargo. 1969. Biological observations on a Neotropical parasocial bee, Eulaema nigrita, with a review on the biology of Euglossinae (Hymenoptera, Apidae). A comparative study. Journal of the Faculty of Sciences, Hokkaido University 17: 271-380.

Silvia Regina de Menezes Pedro ${ }^{1}$

${ }^{1}$ Departamento de Biologia, Faculdade de Filosofia, Ciências e Letras de Ribeirão Preto, Universidade de São Paulo. Av. Bandeirantes, 3900, 14040-901 Ribeirão Preto - SP. silviarmp@ffclrp.usp.br 